\title{
Quasi-Operational Coastal Ocean Nowcast/Forecast Systems
}

\author{
Christopher N. K. Mooers ${ }^{1,2, *}$ \\ ${ }^{1}$ Ocean Prediction Experimental Laboratory (OPEL), Rosenstiel School of Marine and Atmospheric Science (RSMAS), \\ University of Miami, Miami, FL33149-1098 USA \\ ${ }^{2}$ Department of Civil and Environmental Engineering, Portland State University, Portland, OR 97207-0751 USA
}

Received 4 June 2009, accepted 8 June 2009

\begin{abstract}
For several years, quasi-operational (i.e., real-time, semi-autonomous, research-mode) nowcast/forecast systems have been run in two quite different regimes: (1) the Straits of Florida/East Florida Shelf, which includes the Florida Current, and (2) Prince William Sound, Alaska, which is a small, semi-enclosed sea with two major straits. For both regimes, the Princeton Ocean Model (POM) has been implemented with mesoscale resolution. Both implementations are forced by mesoscale numerical weather predictions, the US Navy's operational global ocean model (NCOM, which assimilates satellite altimetric sea surface height anomalies, MCSST, ARGO float temperature and salinity profiles, etc.) for open boundary conditions, and four diurnal and four semi-diurnal tides, also imposed on the open boundaries. Real-time observations are mainly used for model skill assessment, as a prelude to data assimilation. One of the benefits of this activity has been new understanding derived from diagnostics studies made possible by these numerical simulations. For example, the Florida Current Frontal (cyclonic) Eddies, which form weekly in the cyclonic shear zone along the shelfbreak, have been more fully characterized than had been possible by observations alone, and the prevalence of three-layered monthly mean flow in the straits of Prince William Sound has been determined in a highly variable regime that is difficult to observe comprehensively.
\end{abstract}

Key words: Coastal ocean models, Nowcast/forecast systems, Skill assessments, Diagnostic studies

Citation: Mooers, C. N. K., 2010: Quasi-operational coastal ocean nowcast/forecast systems. Terr. Atmos. Ocean. Sci., 21, 181-193, doi: 10.3319/TAO. 2009.06.08.04(IWNOP)

\section{INTRODUCTION}

As the field of Oceanography has advanced in recent decades as a quantitative, predictive science of increasing societal relevance, Operational Oceanography (i.e., the endeavor of producing ocean information products (simulations, hindcasts, nowcasts, forecasts, and re-analyses), with known error characteristics, on a regular, sustained basis for defined user communities addressing societal or scientific applications) has begun to make major strides by combining numerical ocean circulation models with real-time satellite and in situ observations through skill assessment, data assimilation, etc. The societal applications of predictive marine environmental information (e.g., winds, waves, sea surface height, currents, temperature, and salinity) are numerous in support of (1) routine marine operations (e.g., safe and efficient navigation for shipping and boating, com-

\footnotetext{
* Corresponding author

E-mail:cmooers@cecs.pdx.edu
}

mercial and recreational fishing, offshore sand and gravel mining, and oil and gas extraction); (2) emergency management (e.g., search-and-rescue operations, contaminant spill mitigation, harmful algal bloom alerts, storm surge and rip current warnings, and national security activities); and (3) environmental and ecological management (e.g., characterization of variable physical, chemical, etc. attributes of marine habitats; estimation of Lagrangian trajectories and dispersal rates for fish eggs and larvae for input to fisheries recruitment predictions; and the design of effective Marine Protected Areas). The scientific applications are also numerous. For example, a re-analysis conducted with the "best" available modeling, data assimilation, and observational subsystems will provide a retrospective ocean state estimation (including error estimates) for use in diagnostic studies of the ocean as a dynamical system, as part of the climate system, or as a factor in fisheries variability. Not to be overlooked is the intellectual and professional chal- 
lenge afforded by attempting ocean prediction as a means for quantifying contemporary understanding of the ocean system.

As examples of early efforts in the above direction, the Ocean Prediction Experimental Laboratory (OPEL) of the Rosenstiel School of Marine and Atmospheric Science (RSMAS), University of Miami has, for more than a decade, implemented, evaluated, and demonstrated real-time nowcast/forecast systems in a sustained but unofficial (i.e., research or quasi-operational) mode for two domains: Prince William Sound, Alaska (Mooers et al. 2007) and the Straits of Florida (Mooers and Bang 2005), as further discussed below.

The convergence of advances in societal and scientific applications, dynamical understanding, numerical ocean circulation modeling, real-time ocean observing systems, data assimilation schemes, and telecommunications has made the above quasi-operational oceanography activity technically feasible for the first time. In due course, research results from quasi-operational ocean prediction systems will presumably inform the development of formal Operational Oceanography capabilities by official entities. Summarized here are (1) some of the fundamental and useful lessons learned for skill assessment, and (2) some of the serendipitous scientific results accrued as a by-product.

\section{IMPLEMENTATION OF NOWCAST/FORECAST SYSTEMS}

The implementation of two nowcast/forecast systems, the East Florida Shelf (EFS) Information System ${ }^{1}$ (EFSIS) (Mooers and Bang 2005) and the Extended Prince William Sound (EPWS) Nowcast/Forecast System² (EPWS/ NFS) (Mooers et al. 2007), is introduced. They both use the Princeton Ocean Model (POM) as their "numerical engine" (Mellor 2002). The EFS-POM model domain (Fig. 1) includes the Straits of Florida, a $1000 \times 100 \times 2 \mathrm{~km}$ leaky channel between Florida on one side and The Bahamas and Cuba on the other side, with two major passages through the Bahamas. The EPWS-POM model domain (Fig. 2) is Prince William Sound, Alaska, a $100 \times 100 \times 0.5 \mathrm{~km}$ twostrait, semi-enclosed sea, plus the adjacent continental margin. Both regimes are highly stratified. EFS and EPWS both have several operational, real-time coastal tide gauges, surface meteorological coastal stations and offshore buoys, and (intermittently) Acoustic Doppler Current Profilers (ADCPs) (Figs. 1 and 2). EFS also has a volume transport monitoring system (described below), and research-mode coastal HF radar (for surface current mapping) and ADCP systems. EFS-POM is rendered on a curvilinear grid follow- ing the main sweep of the EFS bottom topography, while EPWS-POM is rendered on a Cartesian grid. The horizontal resolution of EFS-POM ranges from about 2 to $20 \mathrm{~km}$, while the horizontal resolution of EPWS-POM is about $1 \mathrm{~km}$. Thus, both EFS-POM and EPWS-POM are mesoscale eddy-admitting. Terrain-following (sigma) coordinates are used in the vertical direction for both EFS-POM and EPWS-POM. They both use over 20 sigma levels, with non-uniform, higher resolution in the nearsurface and nearbottom layers. With EFS-POM (EPWS-POM) driven by real-time open boundary, atmospheric, and tidal forcing, and its real-time output made available to external users, the nowcast/forecast system EFSIS (EPWS/NFS) is constituted. Both EFSIS and EPWS/NFS have their origins in predecessor systems dating from the early 1990s (Mooers and Ko 1994 and Wang and Mooers 1998, respectively). EFSIS (EPWS/NFS) has been running in its present configuration since October 2004 (February 2005), when synoptic open boundary conditions became available from an operational global ocean prediction system [Global-NCOM (Barron et al. 2003)], as described further below.

EFSIS and EPWS/NFS use realistic bottom topography from standard data bases. They are forced by synoptic open boundary conditions, tides, and mesoscale atmospheric forcing. The synoptic open boundary conditions are the horizontal velocity, temperature, and salinity fields extracted from a mesoscale-admitting, data assimilative operational global ocean prediction system (the US Navy's Global-NCOM) which is driven by synoptic scale atmospheric forcing but not tides. The tidal forcing on the open boundaries is obtained from a barotropic run of POM driven by the four major diurnal and semidiurnal tidal constituent amplitudes and phases extracted from publicly available tidal models, and it is then applied to a baroclinic run of POM together with the synoptic open boundary conditions for the normal velocity component (and temperature and salinity) from the global model using a modified Flather radiation boundary condition (Foreman and Thomson 1997). The real-time atmospheric forcing is from publicly available mesoscale numerical weather prediction (NWP) systems; the predicted surface winds are used to calculate the wind stress applied to EFSIS and EPWS/NFS. However, the available surface atmospheric pressure is not utilized in the forcing, resulting in errors in coastal sea level of the order of 0.1 to $1.0 \mathrm{~m}$ due to the dynamical (non-isostatic) response of the coastal ocean which is a correctable oversight. Surface heat flux is emulated by relaxation to sea surface temperature from the large scale model. However, surface moisture flux and riverine and line-source coastal run-off are neglected, which are also correctable oversights.

\footnotetext{
${ }^{1}$ http://efsis.rsmas.miami.edu/

${ }^{2}$ http://epws-nfs.rsmas.miami.edu/
} 


\section{SKILL ASSESSMENT}

To gain confidence in the veracity and utility of nowcast/forecast system results, it is vital to cultivate awareness of the qualitative and quantitative capabilities and limitations of the nowcast/forecast systems by conducting skill assessments. Here, skill assessments focused on dynamical process studies are called model validations, while skill assessments focused on statistical comparisons of field variables are called model verifications. A considerable variety of skill assessment analyses have been undertaken for EFSIS (Mooers and Bang 2005; Mooers and Fiechter 2005) and EPWS/NFS (Bang et al. 2005; Mooers et al. 2007). Several examples focused on the nowcasts are introduced below.
The general circulation of the EFS is predominantly the poleward flow of the Florida Current, which is a segment of the Gulf Stream's baroclinic jet, and which largely fills the Straits of Florida. However, the synoptic flow is marked by seasonal and interannual variations in the strength of the Florida Current and its volume transport, meanders of the jet, mesoscale eddies formed by the interaction of the jet with steep bottom topography, wind-driven coastal countercurrents, and tidal currents. For EFSIS, comparisons are made with surface currents estimated from a coastal High Frequency (HF) radar system ${ }^{3}$ (WERA) deployed looking offshore from Miami. Four-month mean and standard deviation surface current maps (Fig. 3) for the alongshore component $(\mathrm{V})$ indicate close agreement in magnitude and

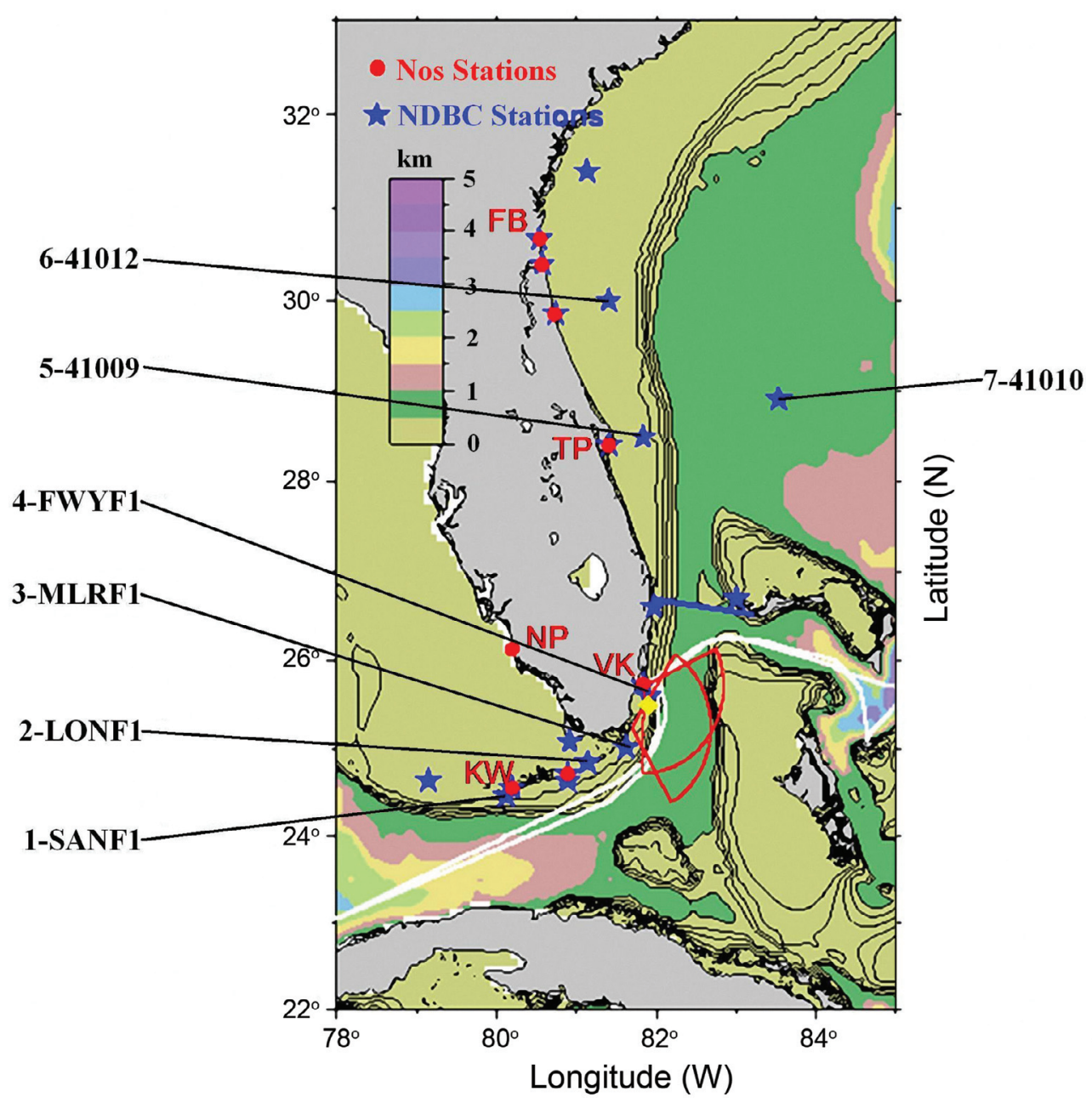

Fig. 1. EFSIS model domain, bottom topography, and real-time observing system elements. National Ocean Service (NOS) stations are coastal tide gauges, National Data Buoy Center (NDBC) stations are real-time meteorological buoys and coastal towers. The blue line corresponds to submarine telephone cable used to monitor volume transport, red arcs define nominal field-of-view for two coastal HF Doppler radars, and white lines delineate Explorer of the Sea (i.e., instrumented cruise ship) weekly cruise tracks, plus a yellow diamond for a delayed-time moored Acoustic Doppler Current Profiler (ADCP). 


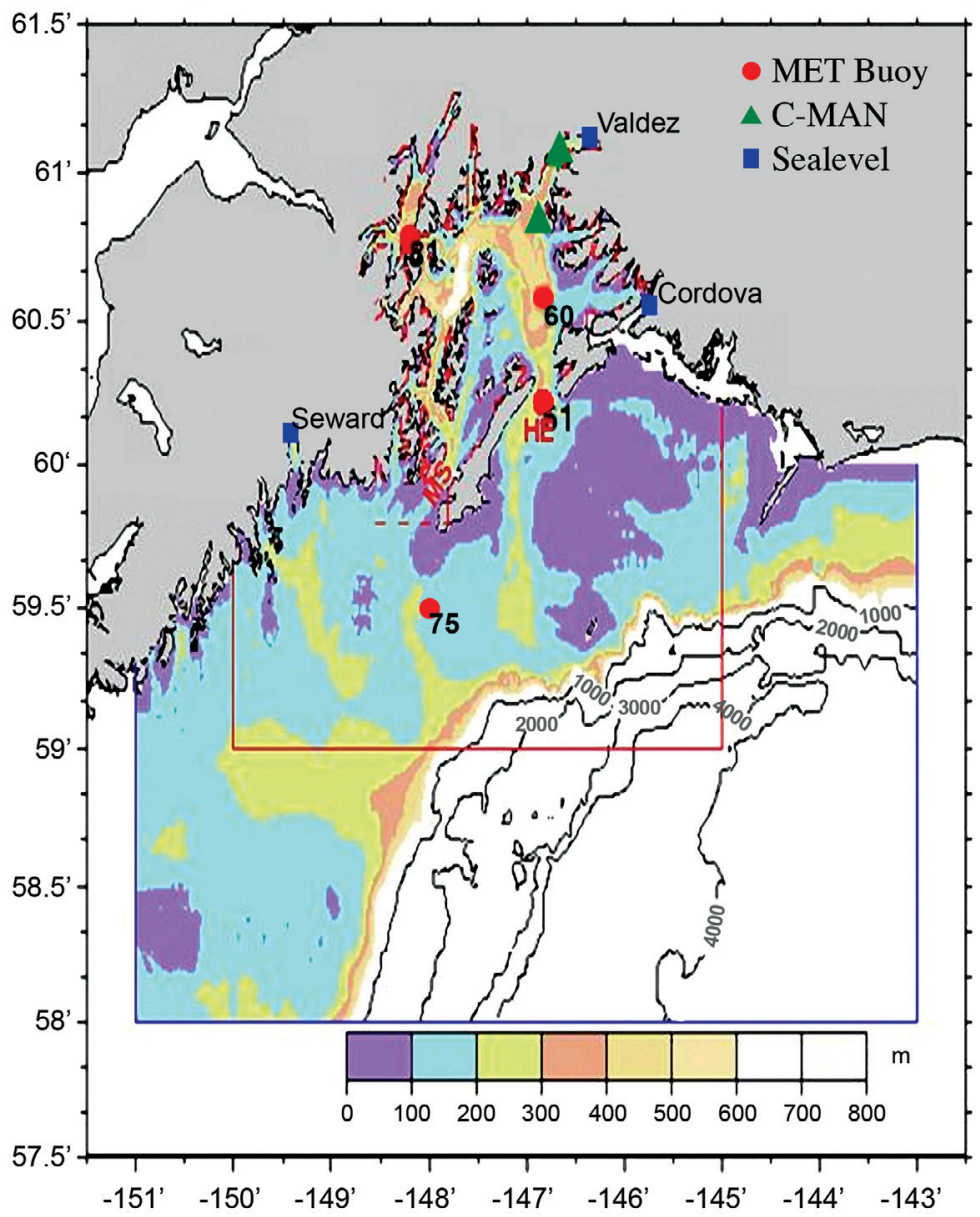

Fig. 2. EPWS/NFS model domain, bottom topography, and real-time observing elements ("sealevel stations" are NOS coastal tide gauges, and "MET buoy" and "C-MAN stations" are NDBC meteorological buoys and coastal towers, respectively). NOTE: NDBC buoy 60 also intermittently included a real-time ADCP.
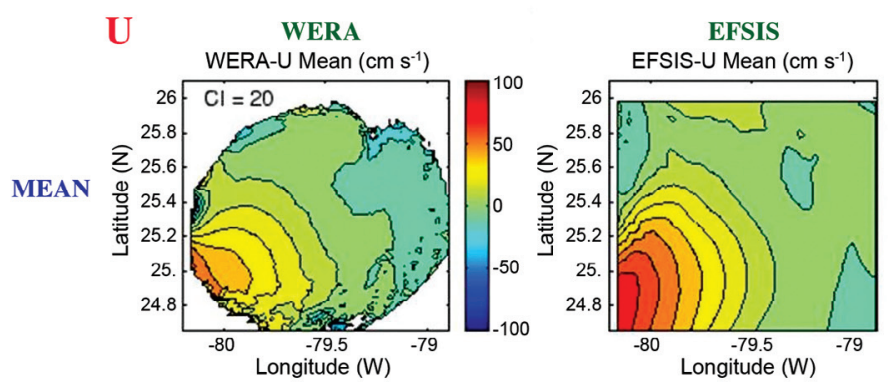

V

WERA

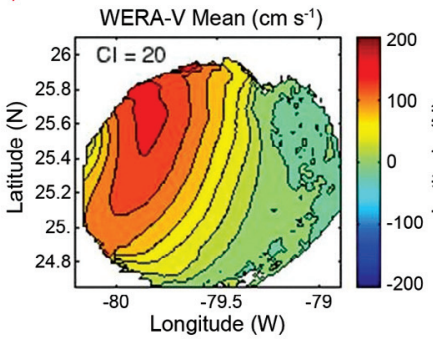

EFSIS-U S.D. $\left(\mathrm{cm} \mathrm{s}^{-1}\right)$
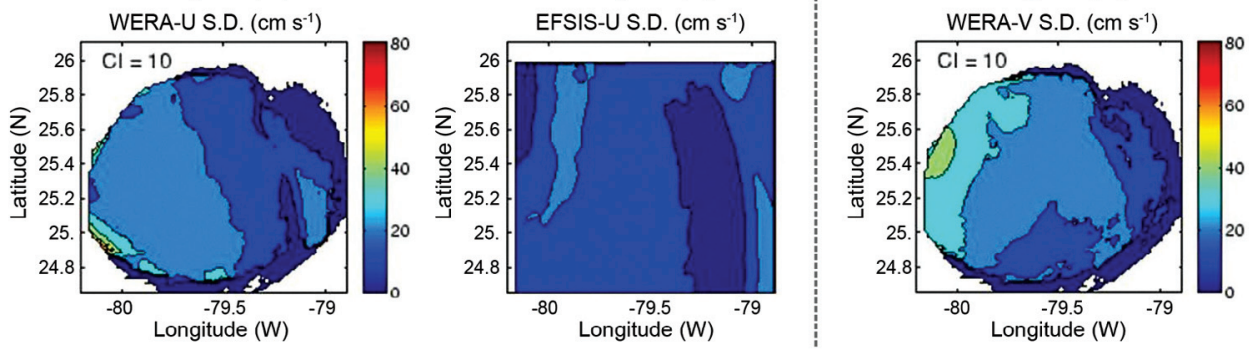

EFSIS

EFSIS-V Mean $\left(\mathrm{cm} \mathrm{s}^{-1}\right)$
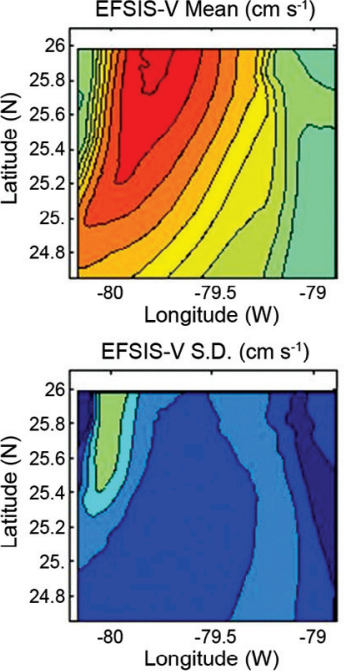

Fig. 3. Four-month mean and standard deviation maps of surface currents (U: cross-shore and V: alongshore components) estimated by coastal HF Doppler radar (WERA) and EFSIS in a subdomain off Miami. 
spatial structure; even the weaker cross-shore component (U) is in appreciable agreement. The Florida Current surface jet is well-defined, as is its downstream acceleration off Miami, which is consistent with the Straits of Florida narrowing and shoaling there. The same datasets are used to compute the spatially-lagged, four-month averaged autocorrelation coefficients relative to a central point for $\mathrm{U}$ and $\mathrm{V}$ for both WERA and EFSIS (Fig. 4). The agreement in asymmetric patterns and magnitudes, and, thus, correlation scales, is indicative of similar dynamics prevailing in the observations and simulations. The nearsurface $(12 \mathrm{~m})$ and nearbottom $(62 \mathrm{~m})$ eight-month time series of horizontal velocity from an ADCP moored on the narrow continental shelf (at a water depth of $85 \mathrm{~m}$ ) off Miami and EFSIS indicate that the flow and the bottom topography are closely oriented in the north-south direction ( $\mathrm{U}$ and $\mathrm{V}>0$ correspond to eastward and northward flows, respectively). The over-plots of their scatter diagrams (Fig. 5) convey the high degree of temporal variability, including substantial reversals of the mainly along-isobath flows, and the similarity in vertical variation of the temporal variability for the ADCP and EFSIS, consistent with surface-trapping of the Florida Current baroclinic jet. Such a comparison of observations at a point with simulations on a grid is inevitably limited due to model resolution over steeply sloping bottom topography. As well as position and depth errors in bottom topography, native subgrid scale bottom topographic variations are not represented by grid point models. In principle, higher resolution model and bathymetric grids should ameliorate such problems in representation, but those approaches may be prohibitively expensive. Alternatively, the bottom topography may be adjusted ("corrected") so as to minimize a well-motivated statistical metric involving the model output and observations.

The general circulation of PWS is not so fully documented as that of the EFS. Most is known about the surface (upper layer) flow, which is dominated by the buoyant throughflow of the Alaska Coastal Current that enters at Hinchinbrook Entrance (HE) and exits at Montague Strait (MS). However, there is substantial seasonal variation, even reversals in surface flows for extended periods. Furthermore, the flow through HE and MS varies strongly with depth, and usually reverses at least once from the surface to bottom. The synoptic flow is dominated by strong tidal currents and frequent baroclinic mesoscale eddies, fronts, and jets. For EPWS/NFS, the phenomenological plausibility of the seasonal evolution of sea surface temperature (SST) and salinity (SSS) in September 2005 is examined (Fig. 6), with a biweekly time sequence of synoptic maps. Notable are the indications of (1) intense mesoscale variability in PWS and on its adjacent continental shelf and their coupling through HE and MS; (2) rapid seasonal cooling through the month; and (3) persistence of the relatively fresh Alaska Coastal Current (and/or the nearby Copper River plume) and its ap-
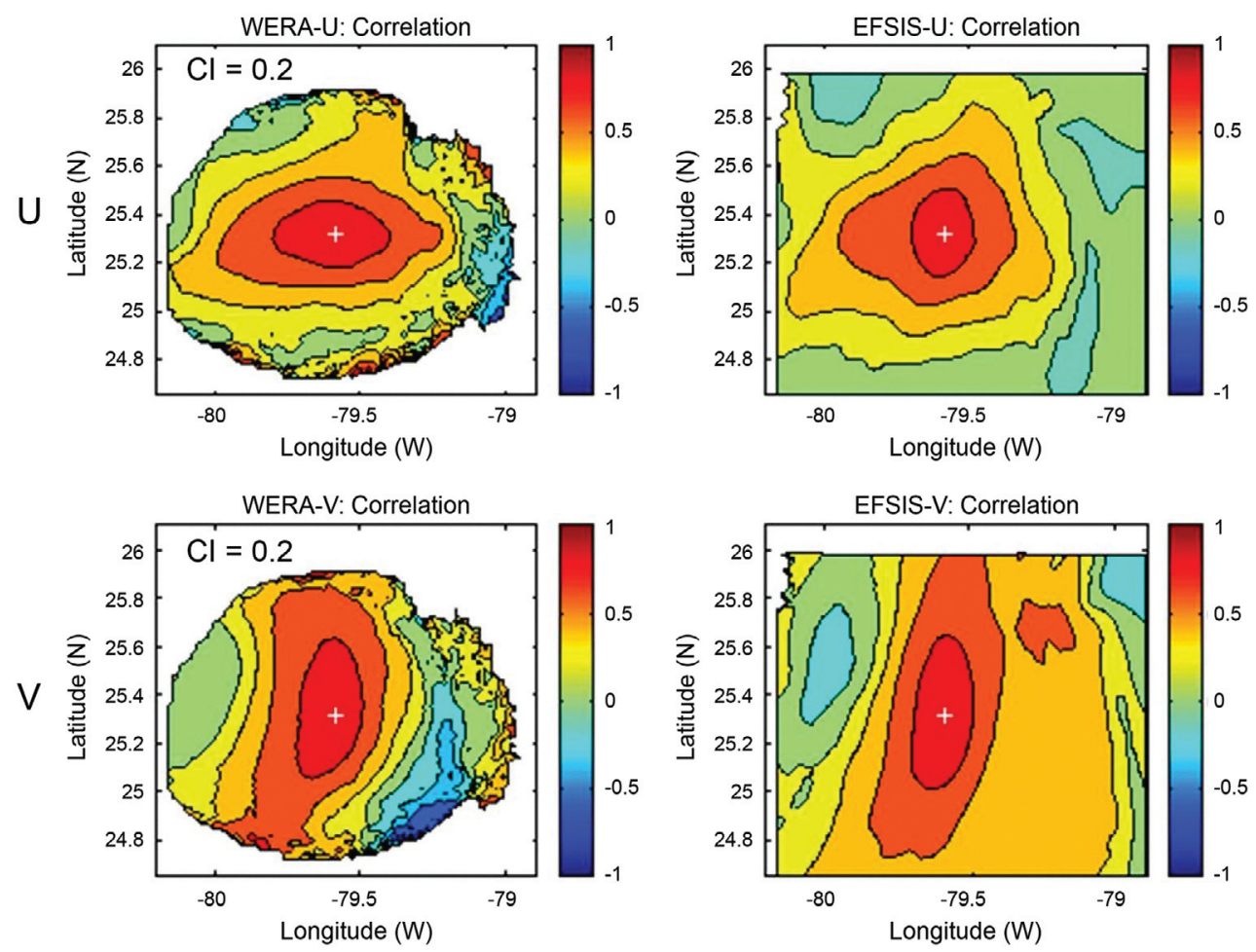

Fig. 4. Spatially-lagged, four-month autocorrelations [relative to the central point (white cross)] for U and V surface current components of WERA and EFSIS estimates (see Fig. 3). 


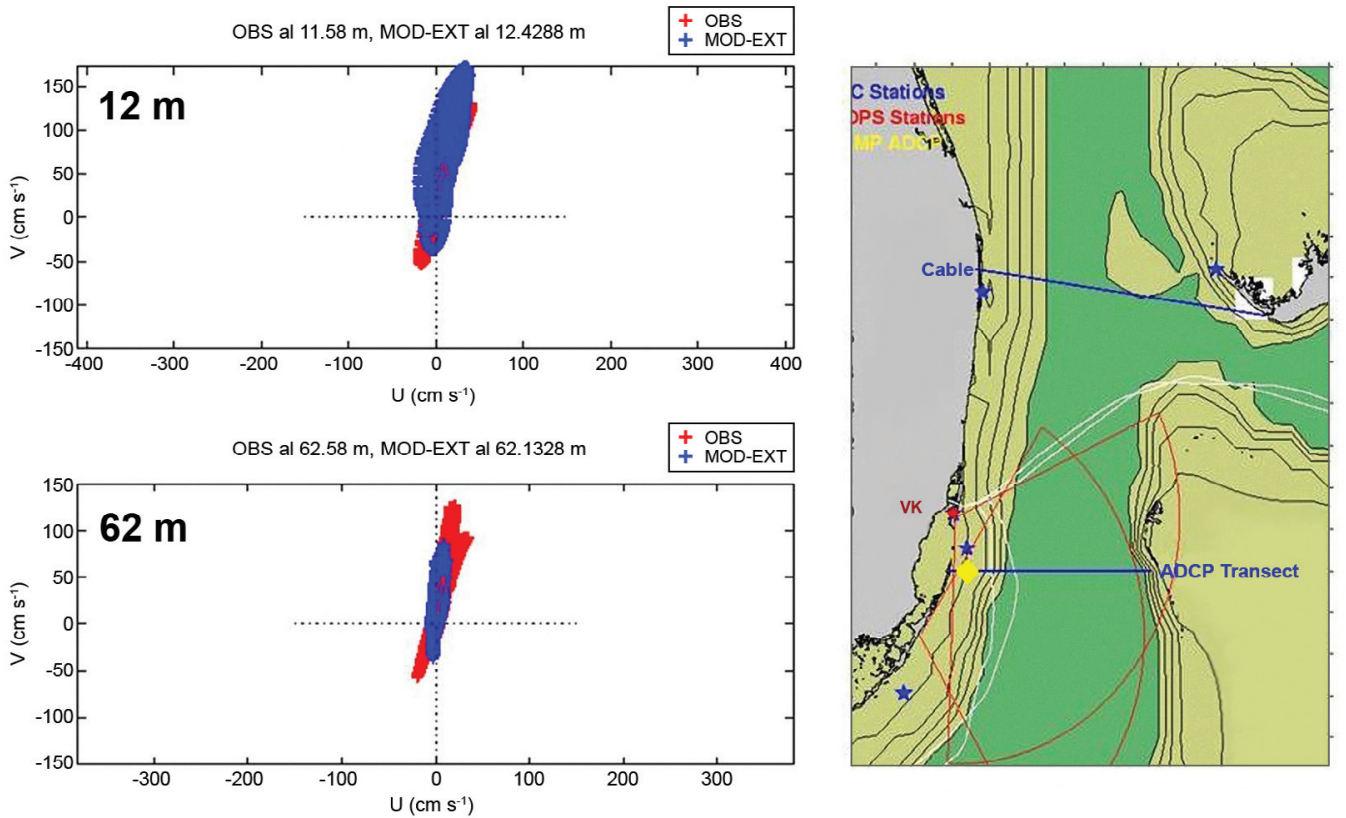

Fig. 5. Eight-month scatter plots of hourly simulated (blue crosses: EFSIS) versus observed (red crosses: OBS) horizontal currents at two levels (12 and $62 \mathrm{~m}$ in left panels, respectively) from an ADCP (yellow diamond in right panel) moored in a water depth of $85 \mathrm{~m}$.
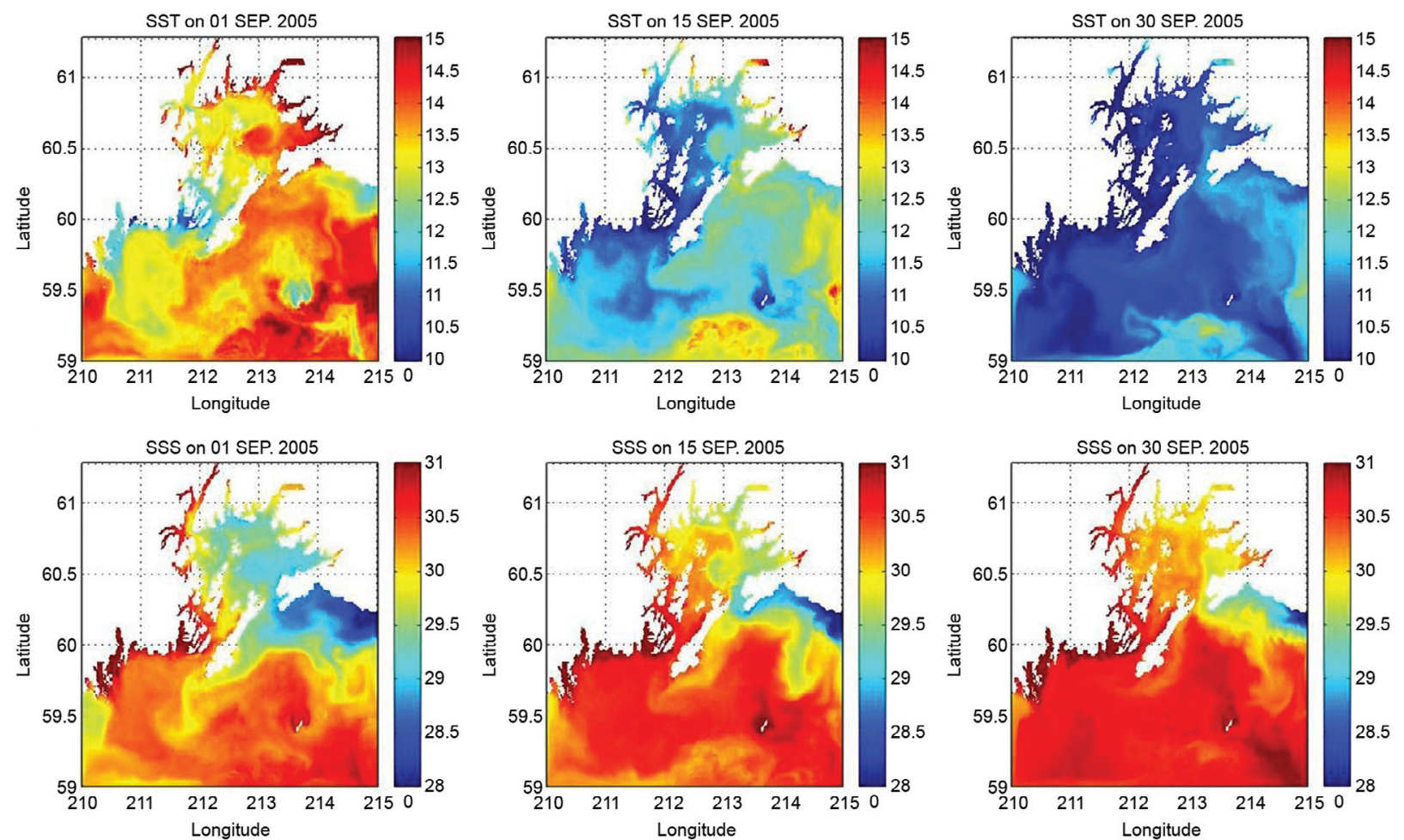

Fig. 6. Biweekly time sequence of synoptic maps of sea surface temperature [SST(deg C)] and sea surface salinity [SSS (psu)] in September 2005 estimated by EPW/NFS.

parent penetration or entrainment into PWS. A long-term, operational meteorological buoy (NDBC 46060) included a downward-looking ADCP for a year or so. One-month time series of ADCP observational values at nearsurface $(26 \mathrm{~m})$, intermediate $(186 \mathrm{~m})$, and nearbottom $(368 \mathrm{~m})$ levels are over-plotted with corresponding simulation values (Fig. 7) to examine the character of the flow. The tidal flows are generally dominant and observed and simulated values sub- 
stantially agree, including their variations with depth. However, there are a few discrepancies of several-day duration at nearsurface and intermediate depths, especially notable for the eastward component. One possible explanation for these discrepancies is that EFSIS may not have adequately estimated surface-trapped mesoscale eddies, for which data assimilation with a more adequate observing system (e.g., surface currents derived from coastal HF radars and/or temperature and salinity profiles from a small fleet of gliders) may be necessary.

The comparison of six-month (winter to summer 2005) mean and standard deviation vertical profiles of horizontal flow components indicate general agreement (Fig. 8), especially in the standard deviations, including a subsurface maxi-
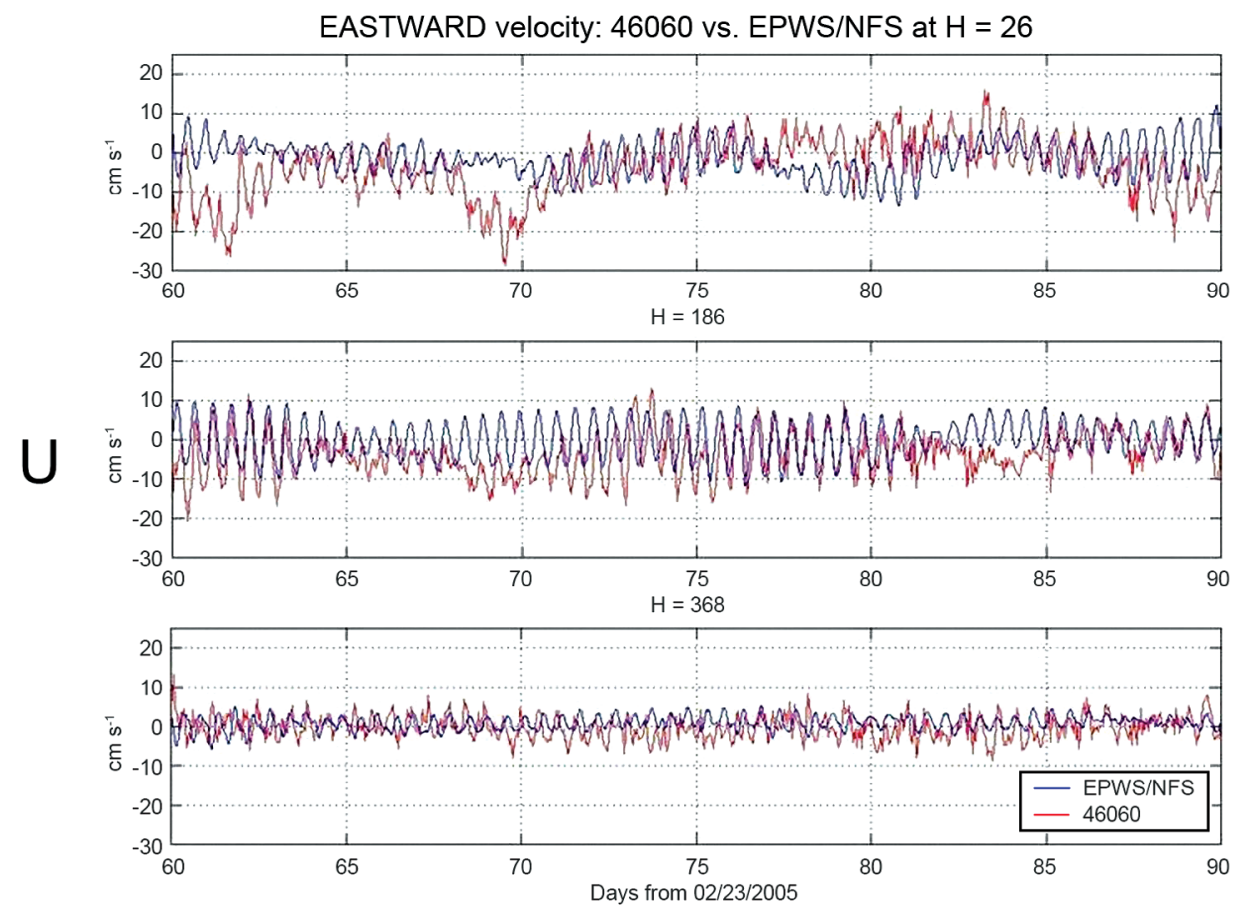

NORTHWARD velocity: 46060 vs. EPWS/NFS at $\mathrm{H}=26$
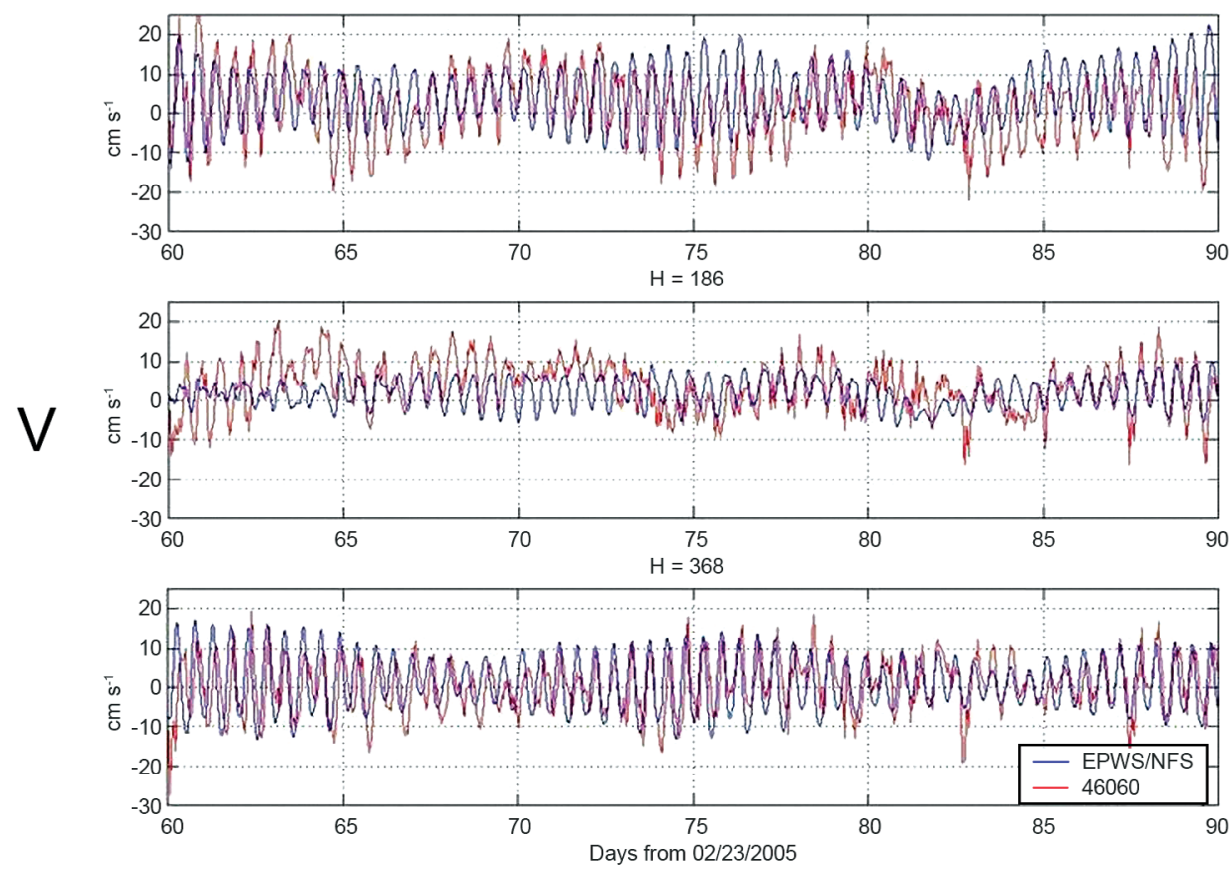

Fig. 7. One-month (April 2005) time series plots of hourly simulated (blue: EPWS/NFS) and observed (red: moored ADCP at NDBC buoy) horizontal current components [U (eastward): upper panels; V (northward): lower panels] at three levels (26, 186, and $368 \mathrm{~m})$ in the center of PWS. 
U

BAROTROPIC

MEAN: $\mathbf{- 5 . 0}$ vs. -1.0

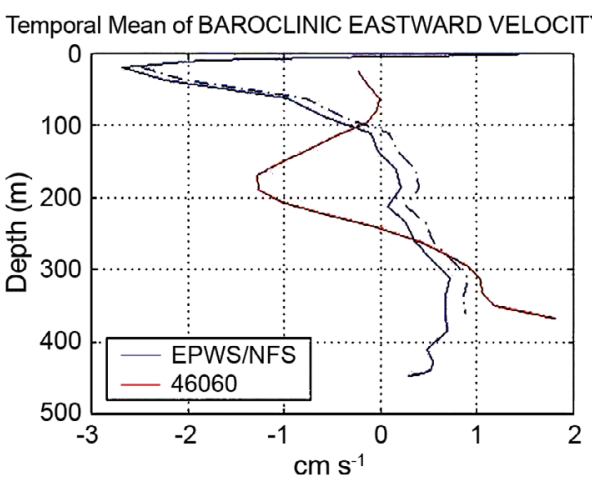

STD

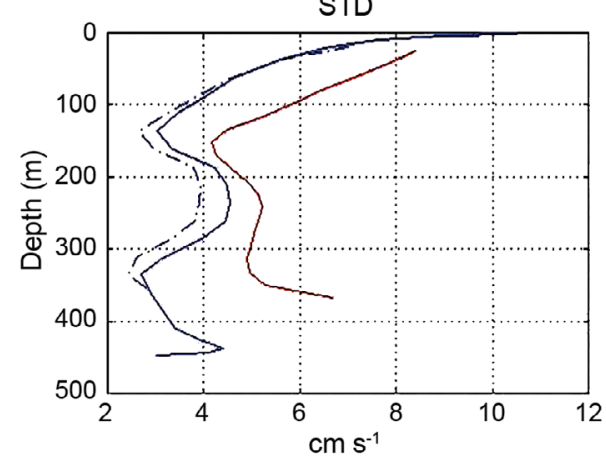

BAROTROPIC

MEAN: 2.3 vs. 5.3
BAROTROPIC

MEAN: -1.6 vs. -2.7
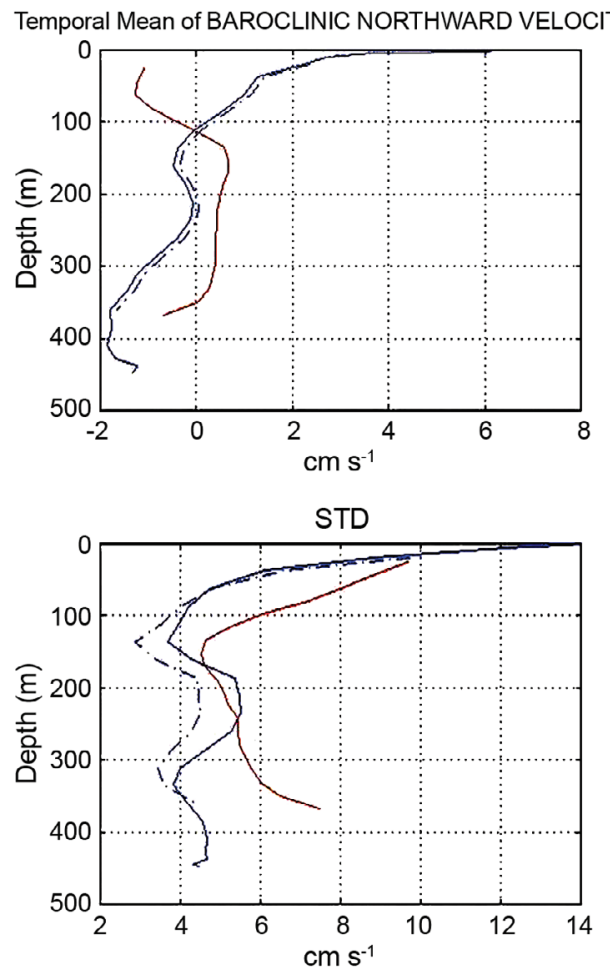

BAROTROPIC

Fig. 8. Six-month mean and standard deviation baroclinic velocity profiles of simulated (blue: EPWS/NFS) and observed (red: moored ADCP at NDBC buoy 60) horizontal current components [U (eastward): left panels; V (northward): right panels]. Mean simulated baroclinic profiles given for barotropic values calculated over full water column (solid blue curve) and over depth-span of observations (dashed blue curve) removed to form baroclinic profiles. Corresponding barotropic (time-averaged and depth-averaged) mean values are also displayed.

mum and strong vertical shears in the upper $100 \mathrm{~m}$. Though the mean flow is relatively weak, the discrepancies are of concern, especially the opposing flow reversals with depth, suggesting a deficiency may exist in the forcing. One possible explanation is that the observed flows are influenced by buoyancy-driven flows due to freshwater run-off and surface moisture fluxes presently overlooked by EFSIS. There are relatively high velocity shears in the upper $20 \mathrm{~m}$, which is above where ADCP velocity values are available, pointing to a possible limitation of the ADCP observing system.

\section{SERENDIPITOUS SCIENTIFIC RESULTS}

In the course of developing and operating nowcast/ forecast systems, unanticipated scientific issues arise, and these systems may offer the means to address these new issues and, thus, produce serendipitous scientific results. A few examples for EFSIS and EPWS/NFS are given below.

In the case of EFSIS, the Florida Current Frontal (cy- clonic) Eddies are generated spontaneously (but they are modulated by the weekly weather cycle) along the shelfbreak with spatial (20 km diameter), temporal (weekly occurrence), and amplitude $\left(0.5 \mathrm{~m} \mathrm{~s}^{-1}\right.$ swirl velocity) scales and translation speed $\left(40 \mathrm{~km} \mathrm{day}^{-1}\right)$ and direction (poleward) consistent with observations (Fiechter and Mooers 2003) (Fig. 9). The upwelling of cool, nutrient-rich subsurface water associated with these eddies "fuels" plankton blooms and, thus, the eddies have ecological and fisheries significance. The volume transport through the Straits of Florida, commonly called the Florida Current volume transport or simply Florida Current transport, is a variable that relates to the meridional transport of the Atlantic Ocean, and to its variability on time scales ranging from weekly to seasonal, interannual, and longer. Hence, it is an important oceanographic metric for model performance. Because the Florida Current is an electrical conductor moving in the Earth's geomagnetic field, a voltage is induced across it that is proportional to the volume transport. The Atlantic Oceanographic 


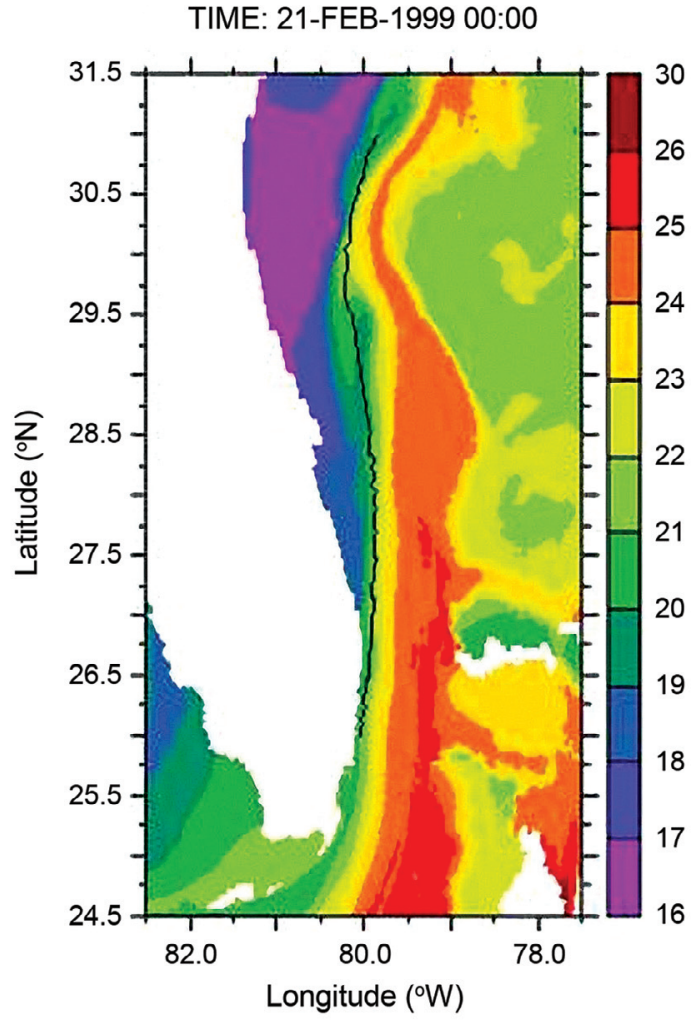

Sea Surface Temperature (deg.C)
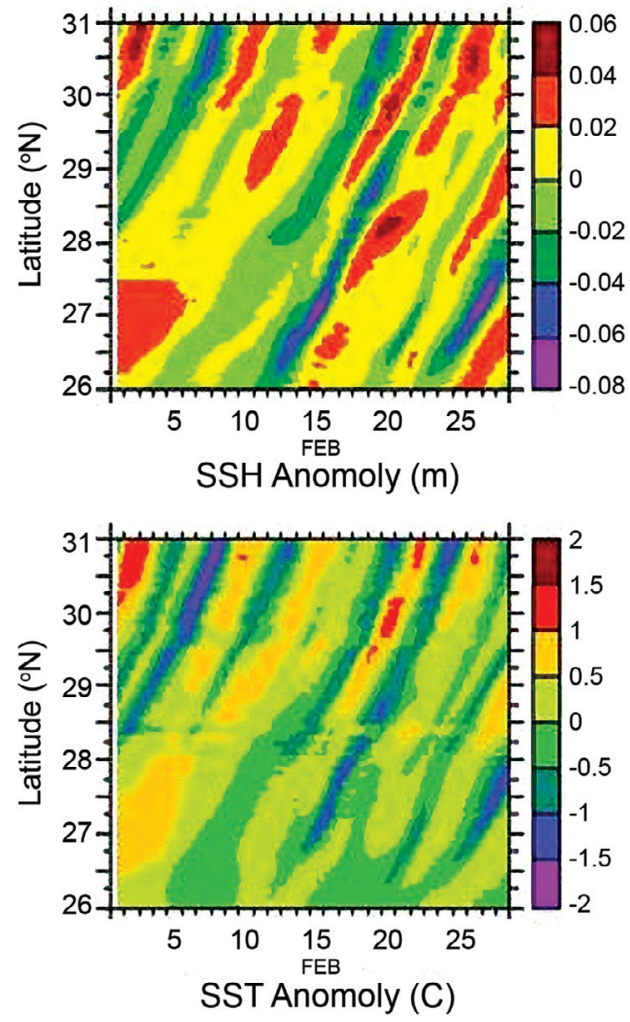

Tronsect along $200 \mathrm{~m}$ isobath

Fig. 9. Florida Current Frontal Eddies (FCFE). Representative simulated synoptic sea surface temperature map (left panel) in the Straits of Florida EFSIS subdomain with a cool anomaly and "shingle" entrainment pattern, both are manifestations indicative of a cyclonic FCFE located near $29.5^{\circ} \mathrm{N}$ at the shelfbreak (black contour: $100 \mathrm{~m}$ isobath). Huvmuller diagrams of sea surface height (SSH: upper right panel) anomaly and sea surface temperature (SST: lower right panel) anomaly taken along the shelfbreak between 26 and $30^{\circ} \mathrm{N}$ for the climatological month of February.

and Meteorological Laboratory (AOML) of the National Oceanic and Atmospheric Administration (NOAA) monitors the induced voltage with an abandoned telephone (submarine) cable on the sea floor between West Palm Beach, Florida and Settlement Point, The Bahamas (Fig. 5). The volume transport estimates of the Straits of Florida from simulations by Global-NCOM and EFSIS are compared with the observed transport estimates made from the submarine cable voltages (Fig. 10). On a time scale of months, there are episodes of strong agreement and others of strong disagreement; these vagaries are not yet understood. However, the weekly weather cycle also induces 10 Sverdrup transport variations in both the observed and simulated Straits of Florida volume transport that agree in magnitude and phase (Mooers et al. 2005). These weekly transport variations are associated with transient wind-driven coastal downwelling (upwelling) events along the East (West) Coast of Florida (The Bahamas). More recent evidence (not shown) indicates that the weather cycle response also includes interactions of the meandering Florida Current with Cape Sal Bank (a large, shallow seamount between Key West, Florida and Havana, Cuba); these interactions of the Florida Current jet with steep bottom topography apparently generate bottom- trapped cyclones that grow and intensify as they translate downstream past Miami. There is limited observational evidence which supports these simulation results for deep cyclogenesis. However, this is a good example of a modelfinding that should lead to future observational studies for hypothesis testing and model validation.

In the case of EPWS/NFS, the annual mean flow through HE and MS is three-layered (Fig. 11); indeed, the mean baroclinic volume transport exceeds the mean barotropic volume transport. The monthly mean flow (not shown) through HE and MS is strongly seasonal, with twolayered flow in winter and relatively strong three-layered flow in summer. The strong seasonally dependent baroclinic transport suggests that PWS has attributes of an estuary as well as those of a semi-enclosed sea. Since EPWS/NFS does not have local runoff or net moisture flux forcing, the buoyancy-driven component would have to be determined from seasonal surface heating and variations in the Alaska Coastal Current as estimated by Global-NCOM (which includes seasonal runoff from the nearby Copper River and other, more distant rivers) or from mixing internal to PWS. In temporal frequency space, there is a transition band for the simulations between the highly coherent, in-phase, low- 
Transports at $27 \mathrm{~N}$

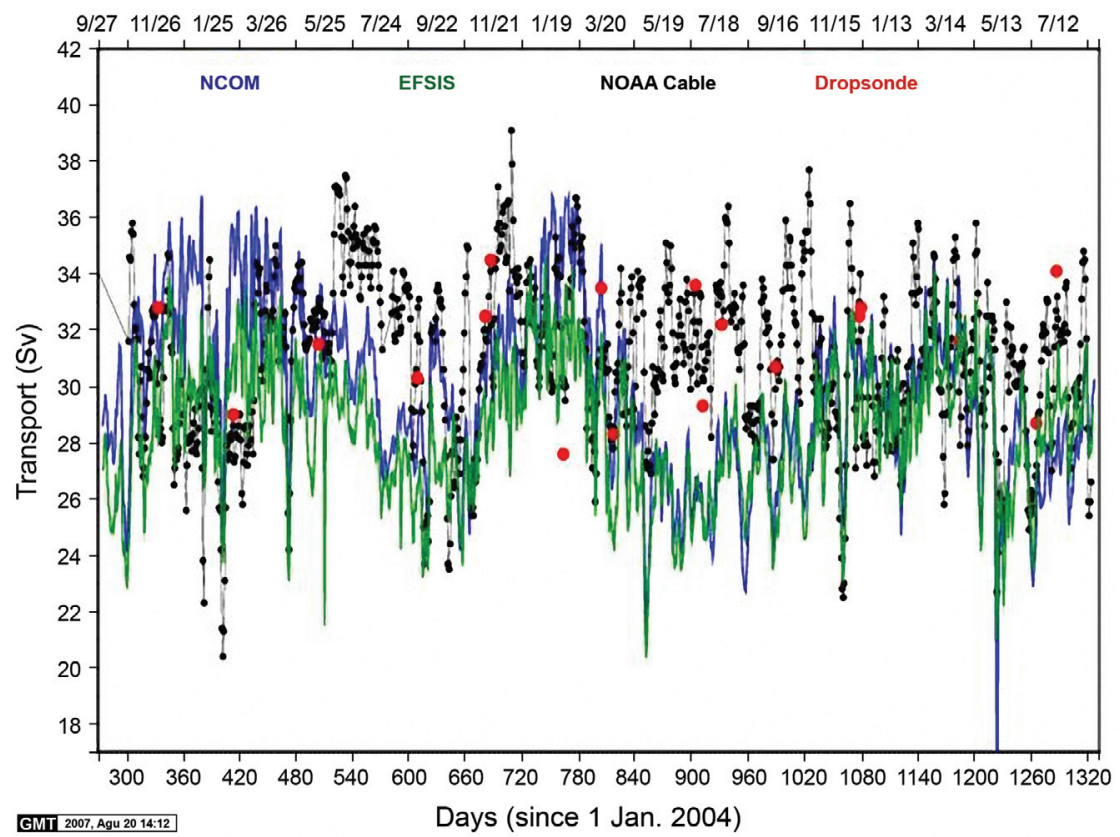

Fig. 10. Six-hourly volume transport time series at $27^{\circ} \mathrm{N}$ in the Straits of Florida from 27 September 2004 to 12 July 2007 estimated by voltages induced in cross-Strait telephone cable (black curve), direct observations (used for cable calibration) from occasional cross-Strait transects with dropsonde profilers (solid red circles), nowcasts from Global-NCOM velocity transects (blue curve), and nowcasts from EFSIS (green curve) velocity transects.
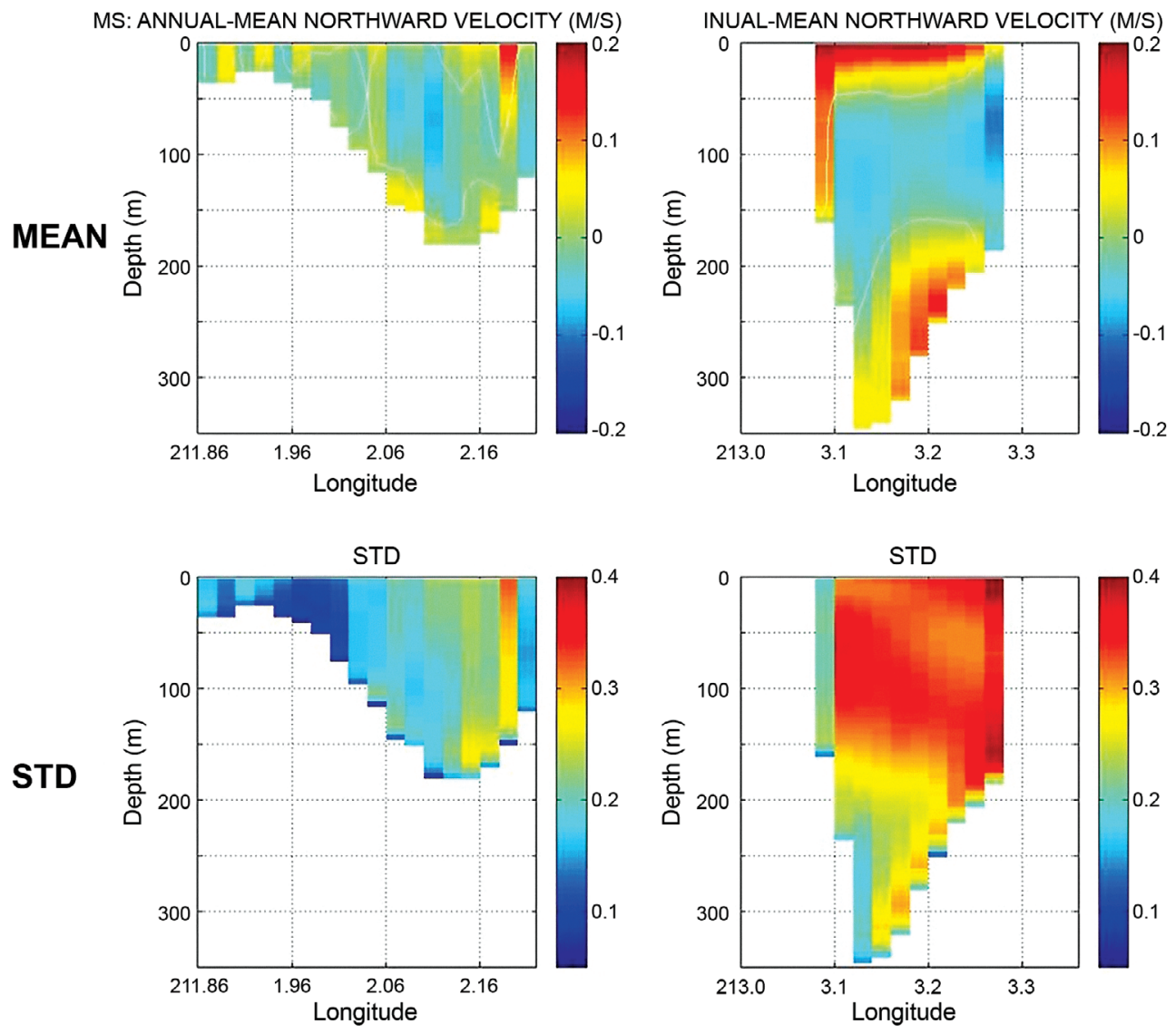

Fig. 11. Annual mean (upper panels) and standard deviation (lower panels) EPWS/NFS simulated along-channel (northward) velocity transects through Montague Strait (MS: left panels) and Hinchinbrook Entrance (HE: right panels) in Prince William Sound (PWS). 
frequency, horizontally non-divergent volume transport and the highly coherent, out-of-phase, high-frequency, horizontally divergent volume transport through the two straits (i.e., $\mathrm{HE}$ and MS). The transition band is in the period range of several hours to a few days, and the motions in this band are relatively chaotic (incoherent) (Fig. 12). The simulated barotropic Helmholz resonance for PWS occurs at a period of six hours, consistent with the theory (Candela 1991) that depends only on the length and cross sectional dimensions of HE and MS and the surface area of PWS.

\section{LESSONS LEARNED}

Based on several years of experience with running EFSIS and EPWS/NFS, and conducting skill assessments, several lessons were learned. For example, the resolution and accuracy of digital data bases for bottom topography continue to be a limiting factor in numerical predictions of coastal ocean circulation. To surmount this obstacle, a multi-disciplinary approach may be needed involving the methods and expertise of satellite geodesists, traditional hydrographic surveyors, and ocean modelers and analysts. The operational open boundary forcing from Global-NCOM is usefully credible and valuable for downscaling (nesting), but, because it is from an operational center, it is inflexible as its model parameters are fixed and a re-analysis capability is not yet available. Until the operational oceanography centers evolve to embrace the needs of the ocean research modelers, as is increasingly done in operational and research meteorology, perhaps the best that can be done is to establish quasi-operational regional centers that use regional open boundary conditions, etc. from a global operational model and, in turn, provide local open boundary conditions for down-scaling to local models. Such regional centers could also conduct regional re-analyses, though they would be limited by the quality of the open boundary conditions derived from the global analyses (nowcasts). The atmospheric forcing available from operational mesoscale NWP provides usefully credible and valuable surface winds and atmospheric pressure, but the validity and utility of the corresponding surface heat and moisture fluxes remains to be examined. To advance this topic, ocean circulation modelers and microscale air-sea interaction researchers need to collaborate on process, sensitivity, validation, and verification studies in a variety of environmental regimes. The tidal forcing available from large scale tidal models that are
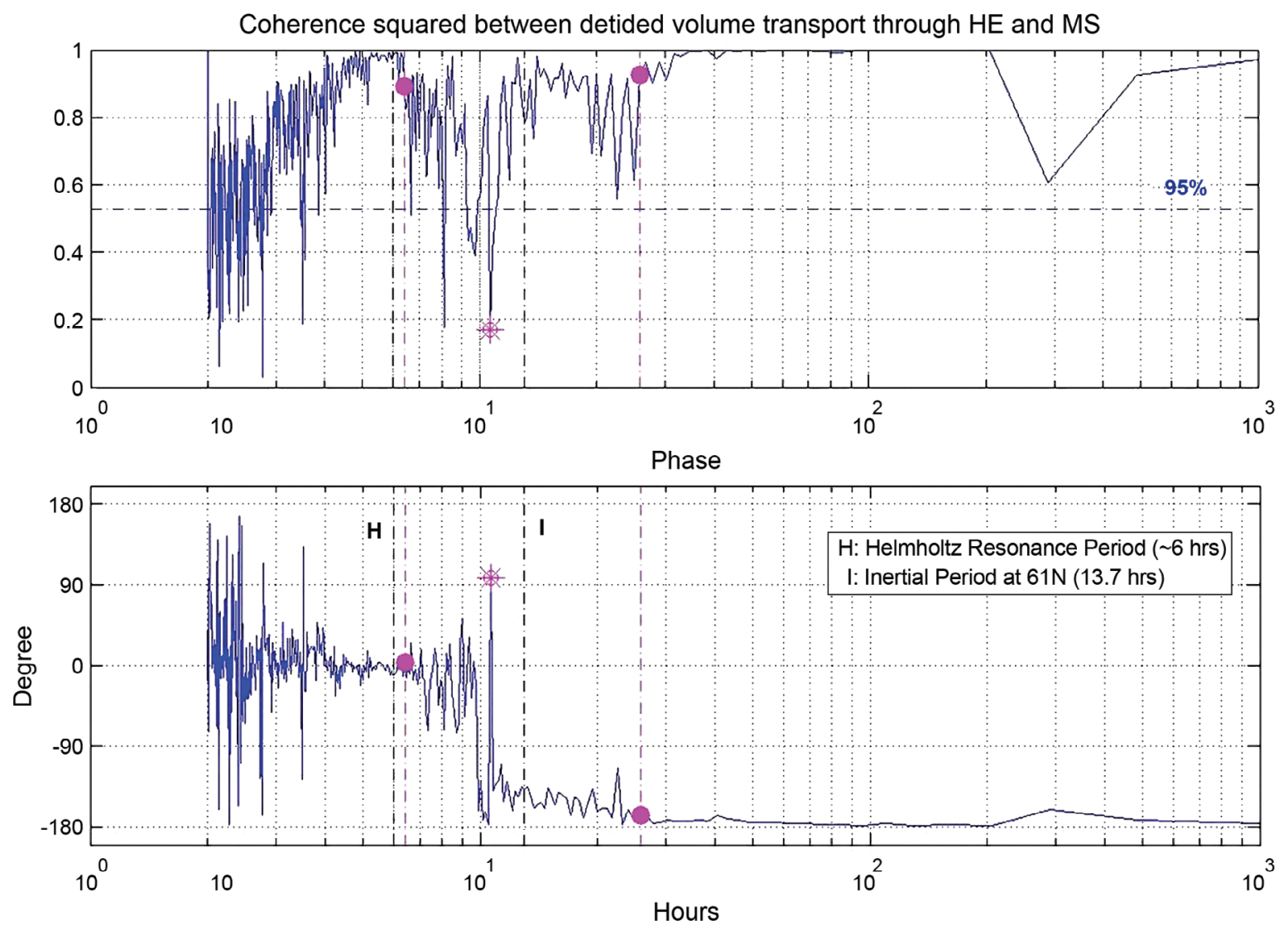

Fig. 12. Coherence squared and phase between volume transport from EPWS/NFS through Montague Strait (MS) and Hinchinbrook Entrance (HE) The solid red circles define (qualitatively) the upper and lower period bounds of the weakly coherent, transition band between the highly coherent, out of phase, long-period horizontally non-divergent transport and the highly coherent, in phase, short-period horizontally divergent transport. 
constrained by satellite altimetric seasurface heights is very adequate for present purposes.

The availability of at least a modicum of validation and verification data is essential to the responsible operation of nowcast/forecast systems because they need continuing skill assessment effort. In the more advanced countries, highquality, coastal tide gauge data are now available in real-time from operational centers. These coastal tide gauge data sets are rich in coastal sea level information that is linked to the broad spectrum of coastal ocean circulation processes and variability that a nowcast/forecast system can be expected to reproduce to a considerable degree. Similarly, there are moored, telemetering ADCPs, available from operational centers and research groups, that provide invaluable time series of vertical profiles of horizontal velocities in realtime. Additionally, coastal HF Doppler radar systems are increasingly available from research groups (but not operational centers yet) to provide synoptic maps of surface currents. Most recently, telemetering autonomous glider (i.e., variable-buoyancy profiler) systems, operated by research groups, have begun to provide repeated, vertical transects of temperature, salinity, and other scalar properties. The data from these modern observing system elements are being incorporated into research models through data assimilation using novel methods tailored to the coastal ocean and the new sensors (cf. Chao et al. 2008; Li et al. 2009; and Wang et al. 2009).

The forcing function fields, as well as the ocean nowcast/forecast predicted fields, need validation and verification. The costal tide gauges and other sensing systems mentioned above are useful for tidal forcing validation and verification, including assessment of the internal tides generated in nature versus predictions. Operational and research moored meteorological buoys and coastal meteorological stations are valuable for validation and verification of atmospheric forcing, especially surface winds, atmospheric pressure, and waves; however, validation and verification of heat and moisture fluxes are more problematic. The validation and verification of the larger scale predicted mass and velocity fields used for downscaling to a regional model are challenging tasks requiring innovative and region-specific approaches. It is reasonable to expect that satellite remote sensing by altimetry, scatterometry, and thermal and color imagery, together with a modest-sized fleet of profiling gliders and surface drifters, would play a large role in the skill assessment of the larger scale model.

As demonstrated here, at this early stage of nowcast/ forecast system development and demonstration, validation and verification studies are likely to lead to discoveries of how the dynamical systems under examination function.

Resources need to be allocated for sensitivity studies. Archives need to be arranged for historical observed time series, transects, maps, etc.; model forcing fields; model output fields; and validation and verification fields.
For validation and verification of Eulerian models, time series of vertical profiles of velocity, temperature, and salinity are needed; in the case of straits, time series of vertical transects of velocity, temperature, and salinity are needed as volume transport alone is insufficient to characterize the flow. However, many of the societal and ecological applications of nowcast/forecast systems require Lagrangian estimates of particle trajectories, advection rates, and dispersion. Hence, for the validation and verification of Lagrangian models (built upon Eulerian models), passive drifters with sensor suites are needed.

The foregoing is presented as a prelude to the use of data assimilation in a nowcast/forecast system because it is important to first establish how well the nowcast/forecast system performs with careful attention to forcing prior to seeking incremental (possibly truly major or only minor) improvements through data assimilation. Following that progression should lead to insights as to the required attributes of, and cost-effective approaches to, both the observing subsystem and the data assimilation subsystem.

Acknowledgements The results presented here depend upon the efforts of Drs. Inkweon Bang, Xinglong $\mathrm{Wu}$, and Jerome Fiechter, OPEL members. Dr. Yu-heng Tseng's editorial assistance was very collegial and capable. The present analysis of EFSIS is a contribution to the Southeast Atlantic Coastal Ocean Observing System (SEACOOS) sponsored by the Office of Naval Research, while the present analysis of EPWS/NFS is a contribution to the Oil Spill Recovery Institute (OSRI) of Cordova, Alaska sponsored by the Ocean Pollution Act of 1990.

\section{REFERENCES}

Bang, I., S. L. Vaughan, and C. N. K. Mooers, 2005: Initial steps toward validation of a seasonal cycle simulation for Prince William Sound Circulation (Flow and Mass) Fields. Cont. Shelf Res., 25, 901-934, doi: 10.1016/j. csr.2004.09.023. [Link]

Barron, C. N., R. C. Rhodes, L. F. Smedstad, P. J. Martin, and A. B. Kara, 2003: Global Ocean Nowcasts and Forecasts with the Navy Coastal Ocean Model (NCOM), 2003 Naval Research Laboratory Review, 175-178.

Candela, J., 1991: The Gibralter Strait and its role in the dynamics of the Mediterranean Sea. Dyn. Atmos. Oceans, 15, 267-300, doi: 10.1016/0377-0265(91)900 23-9. [Link]

Chao, Y., Z. Li, J. D. Farrara, M. A. Moline, O. M. E. Schofield, and S. J. Majumdar, 2008: Synergistic applications of autonomous underwater vehicles and the regional ocean modeling system in coastal ocean forecasting. Limnol. Oceanogr., 53, 2251-2263.

Fiechter, J. and C. N. K. Mooers, 2003: Simulation of frontal 
eddies on the East Florida Shelf. Geophys. Res. Lett., 30, 2151, doi: 10.1029/2003GL018307. [Link]

Foreman, M. G. G. and R. E. Thomson, 1997: Three-dimensional model simulations of tides and buoyancy currents along the west coast of Vancouver Island. $J$. Phys. Oceanogr., 27, 1300-1325, doi: 10.1175/1520-0 485(1997)027<1300:TDMSOT>2.0.CO;2. [Link]

Li, Z., Y. Chao, J. C. McWilliams, and K. Ide, 2009: A three-dimensional variational data assimilation scheme for the regional ocean modeling system. J. Atmos. Ocean. Technol., 25, 2074-2090, doi: 10.1175/ 2008JTECHO594.1. [Link]

Mellor, G. L., 2002: Users Guide for a Three-Dimensional, Primitive Equation, Numerical Ocean Model, Princeton University, Princeton, New Jersey, USA.

Mooers, C. N. K. and D. S. Ko, 1994: Nowcast system development for the straits of Florida. In: Spaulding, M. L., K. Bedford, A. Blumberg, R. Cheng, and C. Swanson, (Eds.), Estuarine and Coastal Modeling III, ASCE, New York, 158-171.

Mooers, C. N. K. and I. Bang, 2005: An assessment of a nowcast/forecast system for the straits of Florida/Florida current regime. J. Ocean Univ. China, 4, 288-292, doi: 10.1007/s11802-005-0049-8. [Link]

Mooers, C. N. K. and J. Fiechter, 2005: Numerical simulations of mesoscale variability in the straits of Florida. Ocean Dyn., 55, 309-325, doi: 10.1007/s10236-0050019-0. [Link]

Mooers, C. N. K., C. S. Meinen, M. O. Baringer, I. Bang, R. Rhodes, C. N. Barron, and F. Bub, 2005: Cross validating ocean prediction and monitoring systems. Eos, Trans., AGU, 86, 272-273, doi: 10.1029/2005EO2900 02. [Link]

Mooers, C. N. K., X. Wu, and I. Bang, 2007: Performance of a nowcast/forecast system for Prince William Sound, Alaska. Cont. Shelf Res., 29, 42-60, doi: 10.1016/j.csr. 2007.09.008. [Link]

Wang, J. and C. N. K. Mooers, 1998: On the Implementation of a three-dimensional circulation model for Prince William Sound, Alaska. Cont. Shelf Res., 18, 253-277, doi: 10.1016/S0278-4343(97)00058-7. [Link]

Wang, X., Y. Chao, C. Dong, J. Farrara, Z. Li, J. C. McWilliams, J. D. Paduan, and L. K. Rosenfeld, 2009: Modeling tides in Monterey Bay, California. Deep-Sea Res. II, 56, 219-231, doi: 10.1016/j.dsr2.2008.08.012. [Link] 